\title{
Goniometric Evaluation and Passive Range of Joint Motion in Chondrodystrophic and Non- Chondrodystrophic Dogs of Different Sizes
}

\author{
Mhayara Reusing ${ }^{1}$ Mayara Brocardo ${ }^{2}$ Saulo Weber ${ }^{1}$ José Villanova Jr. ${ }^{1}$ \\ ${ }^{1}$ Graduate Program in Animal Science, Pontifícia Universidade \\ Católica do Paraná, Curitiba, Paraná, Brazil \\ 2 Pontifícia Universidade Católica do Paraná, Curitiba, Paraná, Brazil \\ Address for correspondence Mhayara Reusing, DVM, MSc, Imaculada \\ Conceição, 1155, Prado Velho, Curitiba, PR 80215-901, Brazil \\ (e-mail: mhaysa@live.com).
}

VCOT Open 2020;3:e66-e71.

\begin{abstract}
Objective This study aimed to evaluate angle values in maximal flexion and extension; the passive range of motion (PROM) of the shoulder, elbow, carpal, hip, stifle and tarsus; and the carpal abduction and adduction of chondrodystrophic (CD) and nonchondrodystrophic (NCD) dogs of different sizes.

Study Design Goniometric evaluation was performed in triplicate using a universal goniometer. $C D$ dogs were categorized into miniature, small, medium, large and giant sizes, whereas NCD dogs were allocated to small- and medium-size groups. Hence, each of the seven subgroups comprised 11 clinically healthy dogs. For data analysis, the Levene test was used to evaluate homoscedasticity. The means of each joint angle with the means in each group as well as the PROM between the CD and NCD groups was compared by the Student's $t$-test; meanwhile, the means of the joint angles and ROM among the sizes were compared by analysis of variance, followed by the Tukey test. In those cases, when no homogeneity variance was observed, the Bonferroni test was used. In every case, $p \leq 0.05$ was considered significant.

Keywords

- dog

- goniometry

- chondrodystrophy

- passive range of motion

Results The articular angles and PROM differed according to the dog size and type, that is, CD or NCD.

Conclusion The goniometric values and PROM of dogs depend on the joint type, dog size and chondrodystrophy status. Further studies are necessary to increase the accuracy of the results and to establish the predominant factors governing the differences discovered.
\end{abstract}

\section{Introduction}

Goniometry, in general, is a technique for measuring angles. It is a simple, viable, non-invasive and inexpensive method that is often used by orthopaedic surgeons and physiotherapists to assess the severity of joint injuries and to monitor a patient's clinical evolution. ${ }^{1,2}$ In this technique, articular angle measurements are captured using a goniometer, which can be the universal, fluid or pendula type, or an electronic goniometer from a smartphone. ${ }^{3}$ The universal model appears to be the most typically used in clinical routine owing to its low cost and practicality. It comprises a 180 or 360 degrees protractor system with two plastic or metal arms. ${ }^{4,5}$

Studies have demonstrated goniometry to be highly reliable for the measurement of range of motion compared with visual or radiographic estimation methods, ${ }^{6,7}$ which typically performed without sedation. ${ }^{8,9}$ Passive range of motion (PROM) refers to the maximal angulation between antagonistic joint received

March 17, 2019

accepted after revision

May 15, 2020
DOI https://doi.org/

$10.1055 / \mathrm{s}-0040-1713825$. ISSN $2625-2325$. (c) 2020 Georg Thieme Verlag KG Stuttgart · New York
License terms

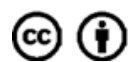


functions, such as flexion and extension or adduction and abduction without muscle contractions, performed by external forces, thereby maintaining the integrity of the anatomical stabilizers of the movement, such as ligaments, tendons and capsules. ${ }^{10,11}$ Goniometric information can be useful in determining the presence of dysfunction, establishing differential diagnoses, ${ }^{12}$ developing the goals of physical rehabilitation treatment, ${ }^{13}$ documenting progress, ${ }^{14}$ modifying treatment and manufacturing orthotics. ${ }^{15,16}$

In veterinary medicine, goniometry has been studied in several species, such as dogs, ${ }^{8,17-21}$ cats, ${ }^{22}$ calves, ${ }^{23}$ sheep, ${ }^{24}$ horses ${ }^{25,26}$ and pacas. ${ }^{27}$ Especially in dogs, it has been reported that universal data can be used as a parameter for goniometric evaluation $^{28}$; however, variations in joint angulations have been discovered between small chondrodystrophic (CD) breeds, such as the Dachshund, and giant-sized non-chondrodystrophic (NCD) breeds, such as the Irish Wolfhund. ${ }^{21,29}$ As the expression of FGF4 retrogene is associated with breeddefining chondrodysplasia, ${ }^{30,31}$ some breeds are typically considered CD, such as the Basset Hound, Dachshund, English Bulldog, French Bulldog, Pug, Shih Tzu and Welsh Corgi. ${ }^{32-34}$

The present study aims to compare the goniometric measurements and range of motion of the shoulder, elbow, carpal, hip, stifle and tarsus joints between CD and NCD of different sizes.

\section{Materials and Methods}

After obtaining approval by the Ethics Committee on the Use of Animals from a local committee under protocol number 0996/2015, the study was performed at the Hospital Unit for Companion Animals at the University, in which 77 young sound adult and female dogs were evaluated. The exclusion criteria used in the study were as follows: immature skeleton (age $<12$ months for miniature-sized dogs and 18 months for other sizes); age greater than 7 years, body condition below $(<4)$ or above $(>6)$ the optimal score from a nine-point body condition scoring system ${ }^{35}$; presence of injury; and metabolic, nervous, muscular, or skeletal diseases. The epidemiological profile and goniometric measurements of each animal were registered in an evaluation form.
Based on breed classification, NCD dogs were classified into the following sizes: miniature $(\leq 5 \mathrm{~kg})$, small (5.1$10.9 \mathrm{~kg})$, medium $(11-25.9 \mathrm{~kg})$, large (26-44.9 kg) and giant $(\geq 45 \mathrm{~kg})$. The CD dogs were of small (5.1-10.9 kg) and medium (11-25.9 kg) sizes. Therefore, each of the seven subgroups comprised 11 dogs for a total of 77 dogs.

Using a universal plastic goniometer (Carci-Industry and Commerce of Surgical and Orthopaedic Apparatus Ltda., São Paulo-SP, Brazil), goniometry was performed on awake dogs in lateral recumbency in triplicate measurements, in which their mean value was considered for statistical analysis. Measurements were obtained by the same examiner, who is experienced and specialized in cat and dog physical therapy to ensure homologous evaluations.

To obtain the joint angular values, the vertex, mobile and static arm of the goniometer was placed over specific anatomical reference points for each joint, ${ }^{36}$ as described in - Table 1.

Another evaluated parameter was the PROM, which is an important factor for assessing joint function, because larger amplitudes are required for walking, trotting and galloping as the speed increases during locomotion. The PROM was calculated by the difference between the maximum extension and the maximum flexion of the joint; meanwhile, it was necessary to add up measurements of both adduction and abduction to obtain the PROM in the transverse plane. ${ }^{37}$

For data analysis, the Levene test was used to evaluate homoscedasticity. The mean of the joint angles and PROM between the $C D$ and NCD groups were compared using the Student's $t$-test, whereas the mean of the joint angles and the range of motion between the groups were compared using analysis of variance, followed by the Tukey test. In cases where no variance in homogeneity was observed, the Bonferroni test was used. ${ }^{38}$ In all cases, $p<0.05$ was applied for significance. Mean values with standard errors were presented. All data were analysed using the Statistical Package for Social Sciences software.

\section{Results}

Differences in joint angles and PROM were observed within dogs of different sizes in the CD and NCD groups. The mean

Table 1 Anatomical references for the correct positioning of parts of the goniometer for each evaluated joint

\begin{tabular}{|l|l|l|l|}
\hline \multirow{2}{*}{ Joint } & \multicolumn{2}{|c|}{ Goniometer parts } & Mobile arm \\
\cline { 2 - 4 } & Static arm & Vertex & Lateral epicondyle of the humerus \\
\hline Shoulder & Spine of the scapula & Subacromial space & Lateral border of the radius \\
\hline Elbow & Major tubercle of the humerus & Lateral epicondyle of the humerus & $\begin{array}{l}\text { Longitudinal axis of the III and IV } \\
\text { metacarpal bones }\end{array}$ \\
\hline Carpus LL & Radius axis & Carpi axis & V metacarpus lateral axis \\
\hline Carpus CC & Lateral epicondyle of the humerus & Styloid process of the ulna & Femoral longitudinal axis \\
\hline Hip & lliac spine & Greater trochanter & Lateral malleolus \\
\hline Stifle & Femoral longitudinal axis & Lateral epicondyle of the femur & V metatarsus lateral axis \\
\hline Tarsus & Longitudinal axis of the tibia & Space between talus and calcaneus &
\end{tabular}

Abbreviations: CC, craniocaudal: for sagittal plane movements; LL, laterolateral: for transversal plane movements. 
Table 2 Mean and standard deviation of articular angles of CD and NCD dogs

\begin{tabular}{|l|l|l|l|l|l|l|l|}
\hline & \multicolumn{2}{|c}{ CD } & \multicolumn{4}{c|}{ NCD } \\
\hline Joint position & Small & Medium & Miniature & Small & Medium & Large & Giant \\
\hline Shoulder flexion & $59 \pm 13^{1}$ & $73 \pm 14^{1,3}$ & $37^{\mathrm{a}} \pm 11$ & $59^{\mathrm{b}} \pm 11$ & $62^{\mathrm{bc}} \pm 10^{3}$ & $70^{\mathrm{c}} \pm 10$ & $58^{\mathrm{b}} \pm 4$ \\
\hline Shoulder extension & $139 \pm 13$ & $138 \pm 13$ & $151^{\mathrm{c}} \pm 5$ & $140^{\mathrm{b}} \pm 9$ & $137^{\mathrm{b}} \pm 8$ & $126^{\mathrm{a}} \pm 12$ & $158^{\mathrm{d}} \pm 7$ \\
\hline Elbow flexion & $31 \pm 8$ & $36 \pm 11^{3}$ & $17^{\mathrm{a}} \pm 3$ & $31^{\mathrm{b}} \pm 7$ & $28^{\mathrm{b}} \pm 3^{3}$ & $36^{\mathrm{c}} \pm 8$ & $29^{\mathrm{b}} \pm 5$ \\
\hline Elbow extension & $153 \pm 30^{2}$ & $135 \pm 14$ & $142^{\mathrm{ab}} \pm 7$ & $151^{\mathrm{bc}} \pm 11^{2}$ & $140^{\mathrm{a}} \pm 8$ & $146^{\mathrm{abc}} \pm 22$ & $154^{\mathrm{c}} \pm 9$ \\
\hline Carpal flexion & $44 \pm 5$ & $43 \pm 7^{3}$ & $29^{\mathrm{a}} \pm 2$ & $40^{\mathrm{bc}} \pm 9$ & $33^{\mathrm{ab}} \pm 6^{3}$ & $47^{\mathrm{c}} \pm 13$ & $44^{\mathrm{c}} \pm 9$ \\
\hline Carpal extension & $193 \pm 7^{2}$ & $176 \pm 18$ & $189^{\mathrm{c}} \pm 2$ & $187^{\mathrm{bc}} \pm 6^{2}$ & $185^{\mathrm{ab}} \pm 5$ & $184^{\mathrm{ab}} \pm 4$ & $182^{\mathrm{a}} \pm 5$ \\
\hline Carpal adduction & $18 \pm 10^{1,2}$ & $4 \pm 6^{1,3}$ & $9^{\mathrm{a}} \pm 2$ & $9^{\mathrm{a}} \pm 9^{2}$ & $18^{\mathrm{b}} \pm 6^{3}$ & $16^{\mathrm{ab}} \pm 9$ & $8^{\mathrm{a}} \pm 3$ \\
\hline Carpal abduction & $53 \pm 7^{2}$ & $48 \pm 10^{3}$ & $51^{\mathrm{d}} \pm 15$ & $35^{\mathrm{c}} \pm 15^{2}$ & $32^{\mathrm{bc}} \pm 9^{3}$ & $24^{\mathrm{ab}} \pm 6$ & $18^{\mathrm{a}} \pm 5$ \\
\hline Hip flexion & $52 \pm 19$ & $54 \pm 15$ & $47^{\mathrm{a}} \pm 13$ & $55^{\mathrm{a}} \pm 12$ & $56^{\mathrm{a}} \pm 11$ & $57^{\mathrm{a}} \pm 11$ & $68^{\mathrm{b}} \pm 10$ \\
\hline Hip extension & $156 \pm 25^{2}$ & $132 \pm 26$ & $151^{\mathrm{c}} \pm 6$ & $129^{\mathrm{ab}} \pm 17^{2}$ & $135^{\mathrm{b}} \pm 9$ & $120^{\mathrm{a}} \pm 15$ & $149^{\mathrm{c}} \pm 10$ \\
\hline Stifle flexion & $41 \pm 9$ & $42 \pm 7^{3}$ & $37^{\mathrm{ab}} \pm 5$ & $34^{\mathrm{a}} \pm 7$ & $30^{\mathrm{a}} \pm 7^{3}$ & $42^{\mathrm{bc}} \pm 14$ & $49^{\mathrm{c}} \pm 8$ \\
\hline Stifle extension & $135 \pm 15$ & $140 \pm 6$ & $11^{\mathrm{bc}} \pm 9$ & $130^{\mathrm{a}} \pm 12$ & $142^{\mathrm{ab}} \pm 8$ & $146^{\mathrm{b}} \pm 14$ & $156^{\mathrm{c}} \pm 9$ \\
\hline Tarsus flexion & $49 \pm 11$ & $50 \pm 12^{3}$ & $29^{\mathrm{a}} \pm 6$ & $37^{\mathrm{ab}} \pm 10$ & $33^{\mathrm{a}} \pm 6^{3}$ & $48^{\mathrm{b}} \pm 12$ & $50^{\mathrm{b}} \pm 14$ \\
\hline Tarsus extension & $178 \pm 18$ & $153 \pm 23$ & $156^{\mathrm{a}} \pm 21$ & $168^{\mathrm{ab}} \pm 25$ & $162^{\mathrm{ab}} \pm 9$ & $175^{\mathrm{ab}} \pm 17$ & $161^{\mathrm{b}} \pm 9$ \\
\hline
\end{tabular}

Abbreviations: CD, chondrodystrophic; NCD, non-chondrodystrophic.

${ }^{1}$ Differences in joint angles between small and medium-sized CD dogs.

${ }^{a-d}$ Differences in joint angles between small- and medium-sized CD dogs. $p<0.05$.

${ }^{2}$ Differences of joint angles between small CD and NCD dogs.

${ }^{3}$ Differences in joint angles between medium CD and NCD dogs.

and standard deviation of the CD and NCD dog's articular angles and PROM are summarized in -Tables 2 and 3 respectively. According to the compared parameters, the following findings were obtained:

1. Different sizes (small and medium) within CD group: small $\mathrm{CD}$ dogs revealed a greater carpal adduction and shoulder flexion, represented by lower values, compared with medium breed dogs. Comparing the PROM CD dogs of different sizes, the small breeds presented greater mobility in carpus and hip joints than the medium ones.

2. Different sizes (miniature, small, medium, large and giant) within NCD group: the maximum flexion angle of the shoulder, elbow and carpus increased according to the size of the animals, that is, the flexion range of these joints in dogs of larger sizes was smaller, except for giant dogs that presented the same flexor range as that of small dogs, as shown in - Fig. 1. The maximal extensor angles in the giant breed dogs indicated greater or equal angle measurements compared with those of the other sizes in all joints, except for the carpus, that is, greater extension measurements were recorded in the miniature-sized dogs. The PROM among NCD dogs of different sizes showed no differences in the elbow, stifle and tarsus joints. However, the miniature NCD dogs presented greater mobility in the hip and both planes of the carpus. The

Table 3 Angular measurements of articular PROM of CD and NCD dogs represented in mean and standard deviation

\begin{tabular}{|l|l|l|l|l|l|l|l|}
\hline & \multicolumn{3}{|c|}{ CD } & \multicolumn{5}{c|}{ NCD } \\
\hline PROM & Small & Medium & Miniature & Small & Medium & Large & Giant \\
\hline Shoulder & $79 \pm 20$ & $65 \pm 20$ & $114^{\mathrm{b}} \pm 9$ & $81^{\mathrm{b}} \pm 16$ & $75^{\mathrm{b}} \pm 8$ & Shoulder & $79 \pm 20$ \\
\hline Elbow & $121 \pm 31$ & $99 \pm 20$ & $125^{\mathrm{a}} \pm 8$ & $120^{\mathrm{a}} \pm 14$ & $112^{\mathrm{a}} \pm 7$ & Elbow & $121 \pm 31$ \\
\hline Carpus CC & $149 \pm 8^{1,2}$ & $133 \pm 19^{1,3}$ & $160^{\mathrm{ab}} \pm 2$ & $146^{\mathrm{ab}} \pm 9^{2}$ & $151^{\mathrm{b}} \pm 9^{3}$ & Carpus CC & $149 \pm 8^{1,2}$ \\
\hline Carpus LL & $71 \pm 14^{1,2}$ & $53 \pm 15^{1}$ & $60^{\mathrm{c}} \pm 14$ & $45^{\mathrm{b}} \pm 19^{2}$ & $50^{\mathrm{b}} \pm 13$ & Carpus LL & $71 \pm 14^{1,2}$ \\
\hline Hip & $104 \pm 18^{1}$ & $77 \pm 27^{1}$ & $103^{\mathrm{b}} \pm 9$ & $74^{\mathrm{a}} \pm 25$ & $79^{\mathrm{a}} \pm 15$ & Hip & $104 \pm 18^{1}$ \\
\hline Stifle & $94 \pm 18$ & $98 \pm 8^{3}$ & $113^{\mathrm{a}} \pm 12$ & $102^{\mathrm{a}} \pm 12$ & $112^{\mathrm{a}} \pm 12^{3}$ & Stifle & $94 \pm 18$ \\
\hline Tarsus & $129 \pm 33$ & $103 \pm 28^{3}$ & $127^{\mathrm{a}} \pm 19$ & $130^{\mathrm{a}} \pm 26$ & $129^{\mathrm{a}} \pm 11^{3}$ & Tarsus & $221 \pm 33$ \\
\hline
\end{tabular}

Abbreviations: $C D$, chondrodystrophic; NCD, non-chondrodystrophic; PROM, passive range of motion.

${ }^{1}$ Differences in PROM between small- and medium-sized CD dogs.

$a, b, c$ Differences in PROM between NCD dogs of different sizes.

${ }^{2}$ Differences in PROM between small CD and NCD dogs.

${ }^{3}$ Differences in PROM between medium CD and NCD dogs. 


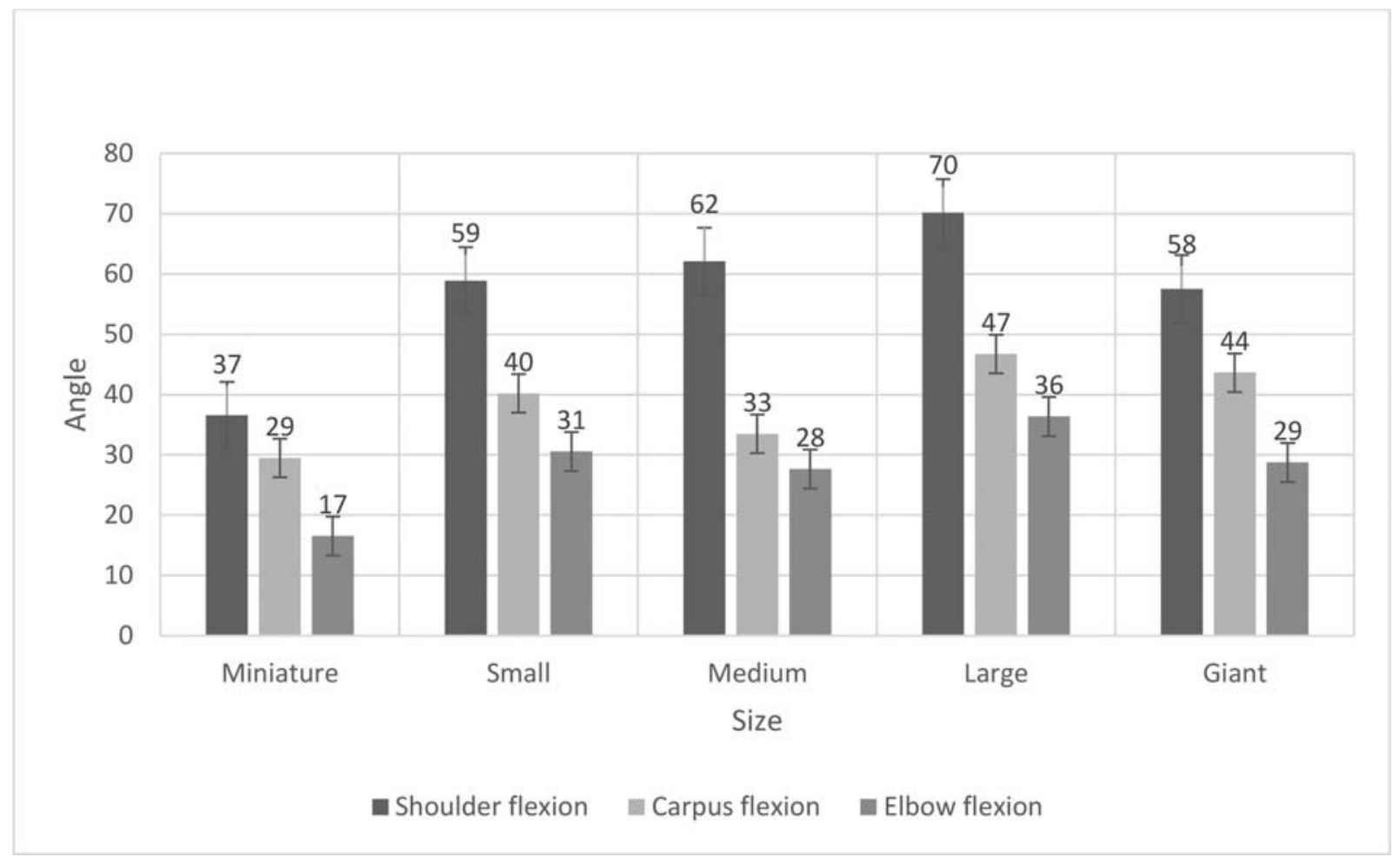

Fig. 1 Means and standard deviation of angular measurements of shoulder, carpal and elbow flexion in non-chondrodystrophic dogs with varying size.

greatest and smallest mobility of the shoulder was presented in the giant and large breed dogs respectively.

3. Small dogs among $C D$ and NCD groups: the extension, abduction and adduction of the carpus and hip extension were larger in the $\mathrm{CD}$ dogs; however, the flexion of the tarsus in this group was less. Regarding joint mobility, the PROM varied only in the hip and carpus articulation in both planes, with the greatest mobility exhibited in the CD dogs. These results show that the smaller $C D$ dogs have greater joint mobility than the larger $\mathrm{CD}$ dogs, that is, the size of the $\mathrm{CD}$ dogs is inversely proportional to their joint mobility.

4. Medium dogs among $C D$ and $N C D$ groups: medium $C D$ dogs presented greater flexor movements in all joints compared with the NCD dogs, except for the hip joint. The medium NCD dogs showed greater carpal adduction, whereas adduction was greater in the smaller dogs. The hip extension angle in the giant breed dogs was higher compared with those of dogs of other sizes. However, the giant breed dogs had a lower hip flexor capacity than the other groups; therefore, they presented greater flexion angles. Despite the differences between angular measurements of the elbow, carpus and hip and joints of small CD and NCD dogs, only the PROM differed in the carpus joints of the medium $C D$ and NCD dogs. The PROM was the same for the shoulder, elbow, hip and carpus in the transverse plane, that is, the variation in the flexor and extensor maximal angulation did not affect the PROM in those joints. Otherwise, the small CD dogs would have a greater tarsal and carpal mobility in the sagittal plane, whereas the medium NCD dogs would exhibit greater mobility in the stifle joints.

\section{Discussion}

In general, a few larger coefficients of variation appeared in each joint goniometry compared with other specific breed studies $8,19,39,40$; this could be because groups were classified by size based on body weight regardless of breed in this study. Another study regarding stifle joints in only large breed dogs showed that this variation might occur between breeds. ${ }^{20}$ Despite the conformational characteristics of different breeds, other determinant factors related to the joint range of motion to be considered are muscle mass and tone, which are typically inversely proportional to the PROM, unless disuse inherent to aging is avoided and mobility exercises are regularly practiced to maintain elongated periarticular soft tissues. ${ }^{11,41}$

The difference between the shoulder joint amplitude in medium and small CD dogs can be explained by the relationship between the diameter of the rib cage and the limb length, which is greater in medium- than in smaller-sized CD dogs, thereby limiting the movement of shoulder flexion by direct contact with the costal grid. ${ }^{21,36}$

Carpal changes in small-sized $C D$ dogs can be explained by the characteristic angular deformity of CD dogs. ${ }^{42,43}$ The early closure of physis in $\mathrm{CD}$ dogs may vary according to the size of the animal and may be directly related to the mobility of the carpus. ${ }^{42-44}$ Furthermore, medium CD breeds have marked developmental characteristics of curved radius, which increases carpal abduction and limits carpal adduction. Additionally, the difference in the adduction and abduction of the carpal joint in $\mathrm{CD}$ dogs may be due to the abnormal development of the radius and ulna, which limits carpal adduction and exacerbates carpal abduction. ${ }^{43}$ 
Differences in hip PROM between CD dogs of different sizes discovered in the present study have not been described sufficiently hitherto. ${ }^{45}$ Other studies regarding Dachshund ${ }^{21}$ and French Bulldogs ${ }^{39}$ showed similar PROM of the hip compared with results obtained in small CD dogs in the present study. No other significant differences existed among the measurements of $\mathrm{CD}$ dogs, which demonstrate the homogeneity of articular angulations in dogs affected by chondrodystrophy. ${ }^{21,36}$

Results of stifle angles of large NCD dogs were compatible with those of a study of Greyhounds ${ }^{46}$; that is, the mean weight was $30 \mathrm{~kg}$; and the mean and standard deviation values of the flexion and extension of stifle were $51 \pm 7$ and $145 \pm 9$, respectively, with less than 10 degrees difference in the mean of the stifle flexion $42 \pm 14$ and extension $146 \pm 14$ of the present study. The same similarity was observed when comparing the hip extension; however, possibly owing to the different breeds analysed in the present study, the hip flexion of $57 \pm 11$ differed significantly from the $72 \pm 8$ observed in the mentioned study, as only Greyhounds were evaluated. The tarsus flexion ( $48 \pm 12$ ) and extension ( $175 \pm 17)$ angles differed from those obtained in the same study (flexion: $110 \pm 10$; extension: $158 \pm 10$ ).

This might be owing to the 90 degrees angle stifle position methodology in the mentioned study. In the present study, the stifle joint was in total flexion, which facilitated tarsus flexion (as reported in other studies), with similar results inferior to 50 degrees for tarsus flexion. ${ }^{21,39}$ Further studies regarding tarsal articulation in dogs are required to compare the results obtained in the present study. ${ }^{17}$ The results obtained through the stifle goniometry of NCD large dogs (flexion $42 \pm 14$ and extension $146 \pm 14$ ) were similar to those reported in another study in seven large breed dogs, in which the means ranged from 29-39 degrees and 154164 degrees for stifle flexion and extension respectively. ${ }^{20}$

The greater mobility in the sagittal and transverse planes of the carpi in the $\mathrm{CD}$ dogs relative to the NCD dogs can compensate for the shorter the limbs. Meanwhile, increased joint mobility favoured joint laxity and the misalignment of the thoracic limbs is the main risk factor of secondary osteoarthrosis. ${ }^{47}$ However, further long-time follow-up studies are required to better understand joint mobility in $C D$ dogs and its possible clinical implications.

\section{Conclusion}

Goniometry is a useful method in dogs to evaluate range and limits of joint motion and may be helpful in planning and executing selected orthopaedic procedures. However, dog size and breed standards should be considered, as the joint angles and PROM differ between CD and NCD healthy dogs of different sizes. Results show that there are differences between PROM and goniometric measurements in CD and NCD dog of different sizes, and this should be considered when applying those evaluation technique.

\section{Authors' Contributions}

M.B. executed the experiment and registered the data. M. R. and S.W. did statistical analysis. J.V., M.R., and S.W. interpreted the results and critically revised the manu- script for important intellectual contribution. All the authors approved the final version.

Conflict of Interest

None declared.

\section{Acknowledgments}

We thank the illustrator Helton Corrêa, Jr, who designed the illustrations in this study.

\section{References}

1 Boone DC, Azen SP. Normal range of motion of joints in male subjects. J Bone Joint Surg Am 1979;61(05):756-759

2 Gordon-Evans WK, Kim S, Kurt S. Fundamentals of Physical Rehabilitation. In: Fossum TW, ed. Small Animal Surgery. 4th edition. St. Louis: Mosby; 2013:114-130

3 Norkin CC, White DJ. Medida do movimento articular: manual de goniometria. 2a ed. Porto Alegre: Artes Médicas; 1997

4 Youdas JW, Bogard CL, Suman VJ. Reliability of goniometric measurements and visual estimates of ankle joint active range of motion obtained in a clinical setting. Arch Phys Med Rehabil 1993;74(10):1113-1118

5 Kramer A, Hesbach AL, Sprague S. Introduction to canine rehabilitation. In: Zink C, Janet B, eds. Canine Sports Medicine and Rehabilitation. 2nd edition. Oxford, England: Wiley-Blackwell; 2018:96-119

6 Gogia PP, Braatz JH, Rose SJ, Norton BJ. Reliability and validity of goniometric measurements at the knee. Phys Ther 1987;67(02): 192-195

7 Thomas TM, Marcellin-Little DJ, Roe SC, Lascelles BDX, Brosey BP. Comparison of measurements obtained by use of an electrogoniometer and a universal plastic goniometer for the assessment of joint motion in dogs. Am J Vet Res 2006;67(12):1974-1979

8 Mendonça GBN. Goniometria em cães da raça Rottweiler. [Masters dissertation]. GoiâniaUniversidade Federal de Goiás2009

9 Figueiredo M, Silva C, Fernandes T, Chioratto R, Tudury E. Exame ortopédico, com e sem anestesia geral, de cães com luxação patelar medial. Arq Bras Med Vet Zootec 2012;64(05):1156-1160

10 Marques AP. Manual de goniometria. 2nd edition. São Paulo: Manole; 2003

11 Millis DL, Levine D, Taylor RA. Range-of-motion and stretching exercises. In: Saunders P, ed. Canine Rehabilitation and Physical Therapy. Philadelphia, PA: WB Saunders; 2014:431-446

12 von Pfeil DJ, Duerr FM. The Orthopedic Examination. Canine Lameness. Fort Collins: Wiley-Blackwell; 2020:31-39

13 Foster S. The Rehabilitation Examination. Canine Lameness. Fort Collins: Wiley-Blackwell; 2020:67-84

14 McCarthy J, Comerford EJ, Innes JF, Pettitt RA. Elbow arthrodesis using a medially positioned plate in 6 dogs. Vet Comp Orthop Traumatol 2020;33(01):51-58

15 Hesbach AL. Techniques for objective outcome assessment. Clin Tech Small Anim Pract 2007;22(04):146-154

16 Zink C, Van Dyke JB. Canine Sports Medicine and Rehabilitation. Hoboken, NJ: Wiley-Blackwell; 2013

17 Alievi MM, Schossler JE, Teixeira MW. Goniometria da articulação tíbio-tarsal após imobilização temporária com fixador esquelético externo em cães. Cienc Rural 2004;34(02):425-428

18 Tomlinson J, Fox D, Cook JL, Keller GG. Measurement of femoral angles in four dog breeds. Vet Surg 2007;36(06):593-598

19 Hady LL, Fosgate GT, Weh JM. Comparison of range of motion in Labrador Retrievers and Border Collies. J Vet Med Anim Health 2015;7(04):122-127

20 Sabanci SS, Ocal MK. Comparison of goniometric measurements of the stifle joint in seven breeds of normal dogs. Vet Comp Orthop Traumatol 2016;29(03):214-219 
21 Thomovsky SA, Chen AV, Kiszonas AM, Lutskas LA. Goniometry and Limb Girth in Miniature Dachshunds. J Vet Med 2016; 2016:5846052

22 Jaeger GH, Marcellin-Little DJ, Depuy V, Lascelles BDX. Validity of goniometric joint measurements in cats. Am J Vet Res 2007;68 (08):822-826

23 Sengöz Şirin O, Timuçin Celik M, Özmen A, Avki S. Measurements of normal joint angles by goniometry in calves. Vet Comp Orthop Traumatol 2014;27(02):120-123

24 Govoni VM, Rahal SC, Agostinho FS, Conceição RT, Tsunemi MH, El-Warrak AO. Goniometric measurements of the forelimb and hindlimb joints in sheep. Vet Comp Orthop Traumatol 2012;25 (04):297-300

25 Adair HS III, Marcellin-Little DJ, Levine D. Validity and repeatability of goniometry in normal horses. Vet Comp Orthop Traumatol 2016;29(04):314-319

26 Liljebrink Y, Bergh A. Goniometry: is it a reliable tool to monitor passive joint range of motion in horses? Equine Vet J Suppl 2010; 42(38):676-682

27 Araújo FAPD, Rahal SC, Machado MRF, Teixeira CR, Lorena SER, Barbosa L. Goniometria dos membros pélvicos de pacas (Cuniculus paca) criadas em cativeiro. Pesqui Vet Bras 2009;29(12):1004-1008

28 Newton CD. Normal Joint Range of Motion in the Dog and Cat. Textbook of Small Animal Orthopedics. London, UK: Lippincott Company; 1985:1101-1106

29 Benson C, Lakey S, Smith M, Hummel-Berry K. A comparison of canine range of motion measurements between two breeds of disparate body types. [abstract]J Orthop Sports Phys Ther 2004:A39

30 Brown EA, Dickinson PJ, Mansour T, et al. FGF4 retrogene on CFA12 is responsible for chondrodystrophy and intervertebral disc disease in dogs. Proc Natl Acad Sci U S A 2017;114(43):11476-11481

31 Parker HG, VonHoldt BM, Quignon P, et al. An expressed fgf4 retrogene is associated with breed-defining chondrodysplasia in domestic dogs. Science 2009;325(5943):995-998

32 Bergknut N, Auriemma E, Wijsman S, et al. Evaluation of intervertebral disk degeneration in chondrodystrophic and nonchondrodystrophic dogs by use of Pfirrmann grading of images obtained with low-field magnetic resonance imaging. Am J Vet Res 2011;72 (07):893-898

33 Forterre F, Gorgas D, Dickomeit M, Jaggy A, Lang J, Spreng D. Incidence of spinal compressive lesions in chondrodystrophic dogs with abnormal recovery after hemilaminectomy for treatment of thoracolumbar disc disease: a prospective magnetic resonance imaging study. Vet Surg 2010;39(02):165-172

34 Eigenmann JE, Amador A, Patterson DF. Insulin-like growth factor I levels in proportionate dogs, chondrodystrophic dogs and in giant dogs. Acta Endocrinol (Copenh) 1988;118(01):105-108

35 Laflamme D. Development and validation of a body condition score system for dogs.: a clinical tool. Canine Pract 1997;22:10-15

36 Petazzoni M, Jaeger G. Atlas of Clinical Goniometry and Radiographic Measurements of the Canine Pelvic Limb. 2nd edition. Milan: Merial; 2008:96

37 Conceição RT, Rahal SC, Agostinho FS, Teixeira CR, Araújo FA, Monteiro FO. Goniometria dos membros torácicos e pélvicos de ovinos em duas faixas etárias. Pesqui Vet Bras 2012;32(08):812-816

38 Magalhães MN, de Lima ACP. Noções de probabilidade e estatística. Editora da Universidade de São Paulo-SPBrazil2002

39 Formenton MR, de Lima LG, Vassalo FG, Joaquim JGF, Rosseto LP, Fantoni DT. Goniometric Assessment in French Bulldogs. Front Vet Sci 2019;6:424

40 Jaegger G, Marcellin-Little DJ, Levine D. Reliability of goniometry in Labrador Retrievers. Am J Vet Res 2002;63(07):979-986

41 Kirkby Shaw K, Alvarez L, Foster SA, Tomlinson JE, Shaw AJ, Pozzi A. Fundamental principles of rehabilitation and musculoskeletal tissue healing. Vet Surg 2020;49(01):22-32

42 Ramadan RO, Vaughan LC. Premature closure of the distal ulnar growth plate in dogs-a review of 58 cases. J Small Anim Pract 1978;19(11):647-667

43 Dennis R. Handbook of Small Animal Radiology and Ultrasound. Churchill Livingstone: Elsevier; 2010

44 Knapp JL, Tomlinson JL, Fox DB. Classification of angular limb deformities affecting the canine radius and ulna using the center of rotation of angulation method. Vet Surg 2016;45(03):295-302

45 Benson C, Lakey S, Smith M, Hummel-Berry K. A comparison of canine range of motion measurements between two breeds of disparate body types: PO270. J OrthopSport Phys 2004;34(01):A39

46 Nicholson HL, Osmotherly PG, Smith BA, McGowan CM. Determinants of passive hip range of motion in adult Greyhounds. Aust Vet J 2007;85(06):217-221

47 Anderson KL, O'Neill DG, Brodbelt DC, et al. Prevalence, duration and risk factors for appendicular osteoarthritis in a UK dog population under primary veterinary care. Sci Rep 2018;8(01):5641 